\title{
Analysis of correlated mutations in Ras G-domain
}

\author{
Ekta Pathak* \\ Bioinformatics Department, MMV, Banaras Hindu University. Ekta Pathak - E-mail: ektavpathak@gmail.com; Phone number: \\ 9651709839; *Corresponding author
}

Received June 11, 2017; Accepted June 21, 2017; Published June 30, 2017

\begin{abstract}
:
Ras GTPases are most prevalent proto-oncogenes in human cancer. Mutations in Ras remain untreatable more than three decades after the initial discovery. At the amino acid level, some residues under physical or functional constraints exhibit correlated mutations also known as coevolving/covariant residues. Revealing intra-molecular co-evolution between amino acid sites of proteins has become an emerging area of research as it enlightens the importance of variable regions. Here, I have identified and analyzed the coevolving residues in the Ras GTP binding domain (G-domain). The obtained covariant residue position data correlate well with the known experimental data on functionally important residues. Therefore, it is of interest to understand these residue co-variations for designing protein engineering experiments and target oncogenic Ras GTPases.
\end{abstract}

Keywords: Ras, GTPases, G-domain, Coevolution, Correlated Mutation

\section{Background:}

Ras GTPases are most prevalent proto-oncogenes in human cancer [1]. Mutations in Ras remain untreatable more than three decades after the initial discovery. The Ras GTP binding domain (G-domain) functions as molecular switches regulating pathways responsible for proliferation and cell survival [2]. An effector molecule, GTPases-activating proteins (GAPs) stimulate the hydrolysis of GTP to GDP to switch off signaling. GDP dissociation and GTP binding is regulated by Guanine nucleotide exchange factors (GEFs) [3, 4]. The binding and hydrolysis of guanine nucleotides cause significant conformational changes in two functional loop regions, Switch I (residue position 25-40) and Switch II (residue position: 57-75) that surround the phosphate group of the nucleotide. The stabilization of the enzymesubstrate complex and the hydrolysis of GTP are facilitated by set of five conserved motifs. G1 (G/AXXXXGKS/T) motif or the Ploop interacts with $\alpha$ - and $\beta$-phosphate groups. A conserved Thr35 residue of G2 (XTX) motif is part of switch I. Thr35 of Ras interacts with $\mathrm{Mg}^{2+}$ and essential for GTP hydrolysis [5]. G2 motif is also called the effectors loop because it is a site for effector and GAP binding. The G3 (DXXG) motif is part of switch II region and provides residues for $\mathrm{Mg} 2+$ binding and $\gamma$-phosphate binding. G4 or N/TKXD motif and G5 or the SAK/L motifs help in guanine recognition [6].

Hidden information about protein structure and function can be extracted by looking at the correlated mutational behavior of the ISSN 0973-2063 (online) 0973-8894 (print)

Bioinformation 13(6): 174-178 (2017) amino acid residues positions [7]. An amino acid substitution, which partly destabilizes the protein structure or function, could be corrected by a substitution at different site [8]. This change in amino acid relative to another is known as correlated mutation or co-evolution or co variation. These residues at some sites strongly affect the evolution of certain other sites in the three dimensional structure of the protein. Residue co-evolution allows protein to maintain its overall structural-functional integrity while enabling it to acquire specific functional modifications $[7,8]$.

Here, coevolving residue positions were identified and mapped onto the Ras G-domain. These residue positions were calculated using multiple sequence alignment of Ras superfamily (Ras, Rab, Ran, Rho and Arf) members. A comprehensive literature survey using PubMed and PubMed central search was performed to retrieve the description of the experimentally verified functional information for the predicted covariant residue positions. The presented correlated mutation data will be of interest to the wet lab experimentalist to unlock the secret behind the action of undruggable Ras.

\section{Methodology:}

\section{Retrieval of Ras G-domain data:}

RAS protein sequence was retrieved from UniProt database (UniProtKB accession number - P78460_HUMAN). PSI-Blast search tool of NCBI was used to identify the homologous sequences of Ras GTPases. The results of PSI-blast search were 
manually screened to include Ras superfamily members such as Rab, Ran, Rho and so on. These sequences were aligned using ClustalX 2.1 tool (http://www.clustal.org/clustal2/). For analysis, only the GTP binding domains that had conserved G1, G2, G3 and G4 motifs were retained, after deleting neighboring domains at their $\mathrm{N}$ and/or $\mathrm{C}$ terminal sides. For structural study, experimental structure of Ras (PDBID: 5P21) was retrieved from the Protein Data Bank (http://www.rcsb.org/pdb).

\section{Prediction of coevolving sites:}

In order to predict the coevolving sites, the MSA file containing the G-domain sequence of Ras superfamily were submitted to InterMap3D server (http://www.cbs.dtu.dk/services/InterMap3D/). InterMap3D predicts co-evolving pairs of amino acids from an alignment of protein sequence [9]. Here, "RCW MI" method was chosen to predict the coevolving positions. The identified Coevolutionary positions were mapped onto the three dimensional structure of the Ras G-domain (PDBID: 5P21) using UCSF Chimera (https://www.cgl.ucsf.edu/chimera/). PubMed and PMC search was performed to retrieve the description of the experimentally verified functional information for predicted covariant residue positions.

\section{Results and Discussion:}

Usually, conserved residue positions are used to identify the functionally important sites in proteins, and a little attention has been given to the residues other than the conserved ones. At the primary structure level, some amino acid residues under physical or functional constraints exhibit correlated mutations or coevolution. Revealing intra-molecular Coevolutionary site has become an emerging area of research as it enlightens the importance of variable regions $[7,8]$.

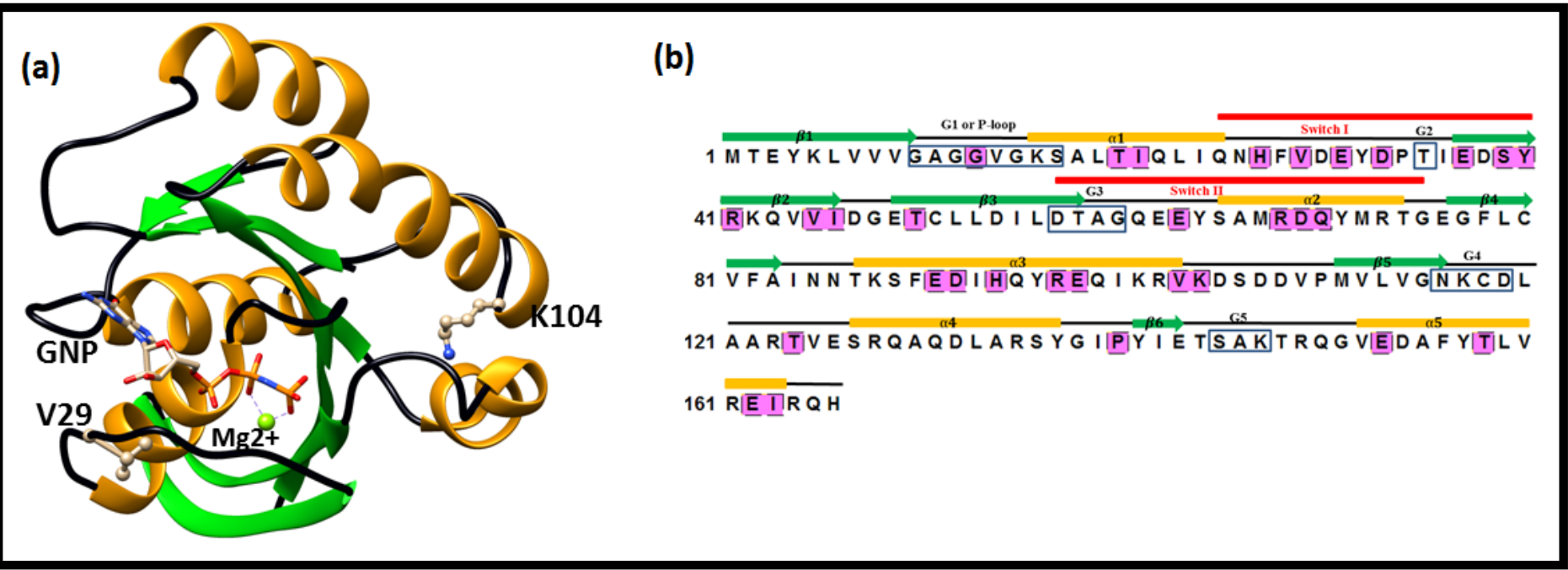

Figure 1. A distribution map of Coevolving residue positions onto the Ras GTPase. A) Ras G-domain (PDBID: 5P21) showing the correlated positions V29 and K104; these two positions showed a high frequency (eight and seven, respectively) of correlated mutations with other residue positions. B) Coevolutionary sites are shown in shaded pink color. G1-G5 motifs are marked with rectangle. Switch I and Switch II regions are shown in red bar.

The coevolving residues in the Ras GTP binding domain were identified and analyzed using InterMap3D (see methods). Mapped onto Ras G-domain; PDBID: 5P21 (Figure 1). A list of 35 pairs of coevolving residue pairs was identified (Table 1). Analysis of covariant residue revealed that Switch I (residue position 25-40) and Switch II (residue position 57-75) of Gdomain harbor seven (H27, V29, E31, D33, E37, S39, and Y40) and four covariant residues (E63, R68, D69, Q70), respectively. The coevolving residues G13, V29, E31 and D33 were observed within $5 \AA$ from the ligand GNP (Figure 1 and Table 2). Noticeably, G13 from p-loop coevolved with V29 of Switch I and a set of four pairs of residues (V29-D69, V29-Q70, S39-E63 and S39-R68) from Switch I-Switch II regions showed co-evolution with each other. The conformational changes at switches depict the active and inactive state of the Ras signaling process [6]. Switch I facilitates
GTP hydrolysis through GAP molecules whereas Switch II selectively binds GEFs to carry out exchange of GTP and GDP [3, 4]. Therefore, presence of coevolving residue positions around the catalytic pocket indicates their role in imparting functional diversity. However, a larger number of covariant site at Switch I, with seven covariant sites, compared to Switch II with four covariant sites suggest a high vulnerability and a larger role of switch I compared to switch II in regulation of GTPase cycle and cellular signaling. It will be of interest to explore the role of correlated amino acid residues, which are located away (more than $5 \AA$ ) from the GTP binding sites (Table 2). These residues are: T20, I21, R41, V45, I46, T50, E92, D93, H95, R98, E99, V103, K104, T124, P140, E153, T158, E162, and I163 (Figure 1 and Table 2). 
Table 1: List of 35 coevolving amino acid residue pairs in Ras G-domain

\begin{tabular}{|c|c|c|c|}
\hline $\begin{array}{l}\text { Amino } \\
\text { Acid }\end{array}$ & $\begin{array}{l}\text { Residue } \\
\text { Position } 1\end{array}$ & $\begin{array}{l}\text { Amino } \\
\text { Acid }\end{array}$ & $\begin{array}{l}\text { Residue } \\
\text { Position } 2\end{array}$ \\
\hline $\mathrm{G}$ & 13 & $\mathrm{~V}$ & 29 \\
\hline $\mathrm{T}$ & 20 & $\mathrm{D}$ & 92 \\
\hline I & 21 & V & 29 \\
\hline $\mathrm{H}$ & 27 & $\mathrm{E}$ & 98 \\
\hline $\mathrm{V}$ & 29 & $\mathrm{D}$ & 33 \\
\hline V & 29 & S & 39 \\
\hline V & 29 & Q & 70 \\
\hline V & 29 & $\hat{\mathrm{D}}$ & 69 \\
\hline V & 29 & K & 104 \\
\hline V & 29 & $\mathrm{~T}$ & 158 \\
\hline E & 31 & $\mathrm{~V}$ & 45 \\
\hline $\mathrm{D}$ & 33 & $\mathrm{R}$ & 41 \\
\hline $\mathrm{D}$ & 33 & K & 104 \\
\hline $\mathrm{D}$ & 33 & $\mathrm{E}$ & 153 \\
\hline $\mathrm{E}$ & 37 & K & 104 \\
\hline$S$ & 39 & $\mathrm{R}$ & 68 \\
\hline$S$ & 39 & D & 92 \\
\hline$S$ & 39 & $\mathrm{~T}$ & 158 \\
\hline $\mathrm{Y}$ & 40 & $\mathrm{E}$ & 63 \\
\hline $\mathrm{R}$ & 41 & K & 104 \\
\hline V & 45 & $\mathrm{E}$ & 162 \\
\hline I & 46 & $\mathrm{~T}$ & 124 \\
\hline $\mathrm{T}$ & 50 & $\mathrm{P}$ & 140 \\
\hline $\mathrm{R}$ & 68 & Q & 70 \\
\hline $\mathrm{D}$ & 69 & $\overline{\mathrm{V}}$ & 103 \\
\hline $\mathrm{D}$ & 69 & K & 104 \\
\hline $\mathrm{D}$ & 69 & $\mathrm{D}$ & 92 \\
\hline $\mathrm{D}$ & 69 & $\mathrm{E}$ & 153 \\
\hline $\mathrm{E}$ & 91 & E & 162 \\
\hline $\mathrm{D}$ & 92 & K & 104 \\
\hline $\mathrm{H}$ & 94 & I & 163 \\
\hline $\mathrm{R}$ & 97 & E & 98 \\
\hline $\mathrm{R}$ & 97 & $\mathrm{~V}$ & 103 \\
\hline V & 103 & K & 104 \\
\hline E & 153 & E & 162 \\
\hline
\end{tabular}

Table 2: A map of coevolving residues onto the Ras G-domain

\begin{tabular}{|c|c|}
\hline G-DOMAIN & Coevolving Residue Positions shown on Ras (PDBID: 5P21) \\
\hline Switch I (Effectors binding site) & H27, V29, E31, D33, E37, S39, Y40 \\
\hline $\begin{array}{l}\text { Nucleotide (GDP/GTP) binding site (Within } 5 \AA \text { of } \\
\text { nucleotide) }\end{array}$ & G13, V29, E31, D33 \\
\hline $\begin{array}{l}\text { Regions away from ligand binding site }(>5 \AA \text { of } \\
\text { nucleotide) }\end{array}$ & $\begin{array}{l}\text { T20, I21, R41, V45, I46, T50, E92, D93, H95, R98 E99, V103, K104, T124, P140, E153, T158, } \\
\text { E162, I163 }\end{array}$ \\
\hline
\end{tabular}

In order to understand, verify and scrutinize the specific molecular and functional role of the reported covariant positions, a comprehensive literature search was performed. PubMed and PMC search revealed that most of the identified covariant residues were associated with regulation of function of Ras (Table 3). As shown in Table 3, implications of covariant residues of G-domain were found reported in regulation of GTPase cycle, effector binding to Switch I and Switch II region, mediation of water molecule in hydrolysis and sharing regions of allosteric sites [10-22]. Intriguingly, V29 position of Switch I and K104, located away from the pocket, (Figure 1A) showed Coevolutionary pattern with eight and seven other residue positions, respectively (Table $\mathbf{1}$ and Table 3 ). Although, analysis of Ras (PDBID: 5P21) revealed that V29 interacts with sugar moiety of GNP (a GTP analog) (Figure 1A), and it is also known to coordinate with conserved water in the catalytic pocket which is essential for hydrolase activity of GTPases [12]. Also, modification at K104 by acetylation affects the conformational stability of the Switch II domain, which is critical for the ability of RAS to interact with guanine nucleotide exchange factors [20]. However, Coevolutionary pressure of eight and seven coevolving residue pairs associated with V29 and K104, respectively, indicate a larger role to be played by these positions, and hence opens up a question for future investigation. 
Table 3: Coevolving residue positions and their known functional implications

\begin{tabular}{|c|c|c|c|}
\hline $\begin{array}{l}\text { Coevolving } \\
\text { residue positions }\end{array}$ & $\begin{array}{l}\text { Degree of } \\
\text { Co-Variation }\end{array}$ & $\begin{array}{l}\text { Functions } \\
\text { (Indicated in literature) }\end{array}$ & $\begin{array}{l}\text { References } \\
\text { (Literature Survey) }\end{array}$ \\
\hline G13 & 1 & Impairs GTP/GDP cycle & [10] \\
\hline T20 & 1 & Not known & NA \\
\hline $\mathbf{I} 21$ & 1 & Plays a crucial role in Switch I transition & [11] \\
\hline H27 & 1 & Not known & NA \\
\hline V29 & 8 & Coordinates conserved water molecule & [12] \\
\hline E31 & 1 & Not known & NA \\
\hline D33 & 4 & Required for interaction with GAP & [13] \\
\hline E37 & 1 & Located at PI3K/Ras interface & [14] \\
\hline S39 & 4 & Located at allosteric site & [11] \\
\hline Y40 & 1 & Located at PI3K/Ras interface & [14] \\
\hline R41 & 2 & Important for SOS-catalyzed nucleotide exchange on Ras & [15] \\
\hline V45 & 2 & Required for interaction with GAP & [16] \\
\hline I46 & 1 & Not known & NA \\
\hline T50 & 1 & Not known & NA \\
\hline E 63 & 1 & $\begin{array}{l}\text { Important for CDC25GEF-mediated conformational changes that decreases } \\
\text { affinity for GDP and increases affinity for GTP }\end{array}$ & {$[17],[18]$} \\
\hline R68 & 2 & $\begin{array}{l}\text { Contributes to order the switch II region and coordinates a water molecule in } \\
\text { active site }\end{array}$ & {$[12],[13]$} \\
\hline D69 & 5 & $\begin{array}{l}\text { Important for CDC25GEF-mediated conformational changes that decreases } \\
\text { affinity for GDP and increases affinity for GTP }\end{array}$ & [18] \\
\hline Q70 & 2 & Not known & NA \\
\hline E91 & 1 & Not known & NA \\
\hline D92 & 4 & Not known & NA \\
\hline $\mathrm{H} 94$ & 1 & Found at allosteric switch & [19] \\
\hline R97 & 2 & R97G found in human tumor; found at allosteric switch & [19] \\
\hline E98 & 2 & Not known & NA \\
\hline V103 & 3 & Not known & NA \\
\hline K104 & 7 & $\begin{array}{l}\text { Acetylation of K104 affects the efficiency of nucleotide exchange and also } \\
\text { suppresses the oncogenic activity RAS. }\end{array}$ & [20] \\
\hline T124 & 1 & Not known & NA \\
\hline P140 & 1 & Not known & NA \\
\hline E153 & 3 & Important for interaction with the membrane. & [21] \\
\hline T158 & 2 & Not known & NA \\
\hline E162 & 3 & Not known & NA \\
\hline I163 & 1 & Located at allosteric site & [22] \\
\hline
\end{tabular}

Here, covariant residues T20, H27, E31, I46, T50, Q70, E91, D92, E98, V103, T124, P140, T158 and E162 were identified as novel sites (Table 3). No experimental report was available, to the best of my knowledge, for these sites. Therefore, it is of interest to understand the role of these residue positions in the functionality of Ras Superfamily and to target oncogenic Ras.

\section{Conclusion:}

Coevolving residue positions are functionally important sites and point mutations at these sites result in conformational change in Ras. Here, residues T20, H27, E31, I46, T50, Q70, E91, D92, E98,

\section{References:}

[1] Karnoub AE \& Weinberg RA, Nat Rev Mol Cell Biol 2008; 9(7): 517 [PMID: 18568040]

[2] Bourne HR et al. Nature 1990; 348(6297): 125 [PMID: 2122258]

[3] Boriack-Sjodin PA et al. Nature 1998; 394(6691): 337 [PMID: 9690470]

[4] Scheffzek K et al. Science 1997; 277(5324): 333 [PMID: 9219684]

ISSN 0973-2063 (online) 0973-8894 (print)
V103, T124, P140, T158 and E162 were identified as novel covariant sites for which functional implications are yet to be discovered. Also, understanding the role of co-variant residues with high frequency of correlated mutation pairs, such as V29 and K104, might open new avenues in designing experiments to target Ras oncogene.

\section{Acknowledgments:}

EP acknowledges Principal, MMV and Dr. Rajeev Mishra, Coordinator, Bioinformatics, MMV, Banaras Hindu University for providing computational facility.

[5] Milburn MV et al. Science 1990; 247(4945): 939 [PMID: 2406906]

[6] Sprang SR Annu Rev Biochem. 1997; 66: 639 [PMID: 9242920]

[7] Socolich M et al. Nature 2005; 437(7058): 512 [PMID: 16177782]

[8] Morcos F et al. Proc Natl Acad Sci U.S.A 2011; 108(49): E1293 [PMID: 22106262]

[9] Gouveia-Oliveira R et al. Bioinformatics 2009; 25(15): 1963 [PMID: 19528088] 


\section{BIOINFORMATION}

\section{Discovery at the interface of physical and biological sciences}

\section{Open access}

[10] Khrenova MG et al. Biochemistry 2014; 53(45): 7093 [PMID: 25339142]

[11] Kapoor A \& Travesset A, PloS one 2014; 9(10): e108846 [PMID: 25272152]

[12] Prakash P et al. PLoS Comput Biol 2012; 8(2): e1002394 [PMID: 22359497]

[13] Lu S et al. Chemical reviews 2016; 116(11): 6607 [PMID: 26815308]

[14] Baussand J \& Kleinjung J, Journal of chemical theory and computation 2012; 9(1): 738 [PMID: 23316125]

[15] Maurer T et al. Proceedings of the National Academy of Sciences 2012; 109(14): 5299 [PMID: 22431598]

[16] Marshall MS et al. Molecular and cellular biology 1991; 11(8): 3997 [PMID: 1906576]
[17] Bunney TD et al. Molecular cell 2006; 21(4): 495 [PMID: 16483931]

[18] Mosteller RD et al. Molecular and cellular biology 1994; 14(2): 1104 [PMID: 8289791]

[19] Buhrman G et al. Proceedings of the National Academy of Sciences 2010; 107(11): 4931 [PMID: 20194776]

[20] Yang MH et al. Proc Natl Acad Sci U.S.A 2012; 109; 10843 [PMID: 22711838]

[21] Gremer L et al. Human mutation 2011; 32(1): 33 [PMID: 20949621]

[22] Buhrman G et al. Journal of molecular biology 2011; 413(4): 773 [PMID: 21945529]

Edited by $\mathbf{P}$ Kangueane

Citation: Pathak, Bioinformation 13(6): 174-178 (2017)

License statement: This is an Open Access article which permits unrestricted use, distribution, and reproduction in any medium, provided the original work is properly credited. This is distributed under the terms of the Creative Commons

Attribution License

ISSN 0973-2063 (online) 0973-8894 (print)

Bioinformation 13(6): 174-178 (2017) 